\title{
A COMPARATIVE STUDY OF ABO BLOOD GROUPS AND SECRETOR STATUS IN ISCHAEMIC HEART DISEASE PATIENTS IN KADAPA CITY
}

\author{
Parveen Shaik ${ }^{1}$, A. Chandra Sekhar ${ }^{2}$
}

${ }_{1}^{1}$ Assistant Professor, Department of Physiology, RIMS, Kadapa, Andhra Pradesh, India.

${ }^{2}$ Associate Professor and HOD I/C, Department of Physiology, RIMS, Kadapa, Andhra Pradesh, India.

ABSTRACT
BACKGROUND
Obesity, hypertension, diabetes mellitus, dyslipidaemia, smoking, stress, sedentary lifestyle and genetic factors are
known risk factors for Ischaemic Heart Disease (IHD). The ABO blood groups and secretor status may be linked to IHD
factors.
Aim- To study the correlation between ABO blood groups and secretor status in the IHD patients in the city of Kadapa.

\section{MATERIALS AND METHODS}

This study was conducted in Department of Physiology, RIMS Medical College, from August 2015 to January 2016. This is a case control study and selection of cases and controls was done by simple random sampling. 600 patients with IHD diagnosed based on the electrocardiograms were chosen from Cardiology Unit, RIMS General Hospital, Kadapa. 600 volunteer blood donor's age and sex matched with no evidence of any disease were included. Blood group estimation was done by slide agglutination method and secretor status was done by indirect haemagglutination method. The sample size required was taken for convenience. Chi-square test and p-value were used for statistical analysis by SPSS S

oftware version 17.

\section{RESULTS}

The frequency distribution among IHD patients was maximum in B group (45.6\%) followed by 0 group (21.6\%), A group (19.9\%) and $\mathrm{AB}$ group (12.7\%). Among the cases, $21.5 \%$ were secretors and $78.5 \%$ were non-secretors and there was a significant association of non-secretors with IHD with Chi-square value of 401.3 and a p-value of 0.00000 .

\section{CONCLUSION}

The results of this study conclude that B group non-secretors are more prone to IHD in the city of Kadapa.

\section{KEY WORDS}

ABO Blood Groups, Secretor Status, Ischaemic Heart Disease.

HOW TO CITE THIS ARTICLE: Shaik P, Sekhar AC. A comparative study of ABO blood groups and secretor status in ischaemic heart disease patients in Kadapa city. J. Evolution Med. Dent. Sci. 2018;7(42):4545-4549, DOI: 10.14260/jemds/2018/1014

\section{BACKGROUND}

At the turn of $20^{\text {th }}$ century, Karl Landsteiner first described the existence of serological differences between individuals and stated that people of the world, irrespective of their race can be divided into four groups depending on the substances present on the surface of their red blood cells. In 1901, he grouped the individuals into $\mathrm{A}, \mathrm{B}, \mathrm{AB}$ and $\mathrm{O}$. The discovery of the iso-agglutinogens was a milestone in the field of medicine. Karl Landsteiner received the Nobel prize for his discovery of the ABO system of blood groups.(1)

The A, B and 0 genes all locate together at $9 \mathrm{q} 34.1$ - $\mathrm{q} 34.2$. The genes of the ABO system do not encode directly for the antigens, but encode for enzymes that add specific sugars to the red cell membrane. These sugars are the ABO red cell antigens that are detectable with serological testing. The $\mathrm{A}$ gene codes for the transferase $\alpha^{(1,2)}$

'Financial or Other Competing Interest': None.

Submission 22-08-2018, Peer Review 27-09-2018,

Acceptance 03-10-2018, Published 15-10-2018.

Corresponding Author:

Dr. A. Chandra Sekhar,

Associate Professor,

Department of Physiology,

RIMS, Kadapa-516001,

Andhra Pradesh, India.

E-mail: sekharphysiology@gmail.com

DOI: $10.14260 /$ jemds/2018/1014
$\mathrm{N}$-acetylgalactosamine transferase and the $\mathrm{B}$ gene codes for transferase $\alpha[1,2]$ galactosyl transferase and 0 allele encodes for non-functional transferase.(3)

The ABH antigens are found not only on red cells, but also on other cells in the most body fluids and on the cell membranes of tissues such as intestine, urothelium and vascular endothelium. The expression of $\mathrm{ABH}$ antigens into body fluids is controlled by the Sese genes and they are located on chromosome 19q13.3.(2)

There is some evidence that ABO blood groups may be associated with certain diseases. Gastric cancer has been reported to be more prevalent in individuals with blood group A, but peptic ulcer is more often seen in those with blood group $0 .{ }^{(4)}$

The term $\mathrm{ABH}$ secretor refers to secretion of $\mathrm{ABO}$ blood group antigens in fluids such as saliva, sweat, tears, semen and serum. Approximately, $80 \%$ of people are secretors (SeSe or Sese). People who do not secrete their blood type antigen in their secretions are termed non-secretors. About 15\% of the population are non-secretors. For example-

- O Group secrete H antigens.

- A group secrete $\mathrm{A}$ and $\mathrm{H}$ antigens.

- B group secrete $B$ and $H$ antigens.

- $\mathrm{AB}$ group secrete $\mathrm{A}, \mathrm{B}$ and $\mathrm{H}$ antigens.(5)

IHD is a condition in which there is an inadequate supply of blood and oxygen to a portion of the myocardium. It 
typically occurs when there is an imbalance between myocardial oxygen supply and demand.(6) IHD causes more deaths and disability and incurs greater economic costs than any other illness in the developed world. Risk factors that are associated with IHD are high fat and energy rich diet, smoking, sedentary lifestyle, obesity, insulin resistance and type II diabetes mellitus. $(6,7,8)$ The way to reduce Coronary Artery Disease (CAD) risk include eating a healthy diet, regular exercise, maintaining a healthy weight and not smoking.(9)

\section{MATERIALS AND METHODS}

\section{Study Design/ Method of Study}

This is a case-control study, which is a type of observational study.

\section{Method of Sampling}

Simple random sampling was used among cases and controls.

This study was conducted between August 2015 and January 2016 in RIMS General Hospital, Kadapa, Andhra Pradesh state, India. Case sheets were filled for the IHD patients and control subjects to obtain their medical history and socio-demographic parameters (Age, sex, educational status, occupation, blood groups and willingness to participate in the study). The sample size required was taken for convenience.

\section{Cases}

The study included a total of 600 IHD patients. The IHD was diagnosed based on ECG taken who came to Cardiology unit, RIMS General Hospital, Kadapa complaining of chest pain. Patients were selected at random after admission from ICCU (Intensive Coronary Care Unit). Patients of both sexes were selected in the age group of 25 - 65 years. 600 patients were studied, among them 444 were males and 156 were females.

\section{Controls}

600 Control subjects were recruited for this study from the healthy volunteer blood donors with no evidence of any disease who came to blood bank, RIMS General Hospital, Kadapa.

Both males and females of ages ranging from 25 to 65 years were recruited. Among 600 controls, 412 were males and 188 were females.

\section{Blood Group Determination}

Blood group was determined by slide agglutination technique.

\section{Principle}

The surface of the red cell membrane contains genetically determined antigens called agglutinogens, while plasma contains antibodies called agglutinins. To determine the blood group of a person, his/ her red cells are made to react with sera containing agglutinins. The slide is then examined under a microscope to detect the presence or absence of clumping and haemolysis of red cells that occurs as a result of antigen-antibody reaction.

\section{Materials}

Antisera, slide, lancet, compound microscope.

\section{Procedure}

Under aseptic precautions, the pulp of the ring finger was pricked by a sterile lancet and one drop of anti-A was placed on one side of a microscopic slide and labelled as A. One drop of anti- $B$ was placed on the other side of the same slide and labelled as B. A drop of blood was added to each drop of antiserum. Blood groups were determined as follows-

- Agglutination in slide A- Blood Group A

- Agglutination in slide B- Blood Group B

- Agglutination in both slides- Blood Group AB

- Agglutination in neither slide- Blood Group 0

\section{Determination of Secretor Status}

It is determined by Haemagglutination inhibition technique.

\section{Principle}

If the blood group antigens are present in saliva when an appropriate antiserum is added to it, an antigen-antibody reaction occurs. The antibodies in the serum neutralise the antigens in saliva. When a red cell suspension of the same blood group is now added to this mixture, there is no agglutination due to previous inhibition of the antiserum. Thus, in the case of secretors there will be no agglutination seen. In the case of non-secretors, as their saliva does not contain blood group antigens, the antiserum added will not be inhibited by the antigens. Now when the red cell suspension of the same blood group is added to the mixture and there will be an agglutination reaction. Thus, in case of non-secretors, there will be agglutination.

\section{Materials}

1. $5 \%$ red cell suspension.

2. Antiserum (Anti-A, Anti-B, Anti-H)

3. Diluted and processed saliva.

4. Test tube rack with tubes.

5. Pipette.

6. Microscope.

7. Slide.

8. Centrifuge.

9. Hot water bath.

10. Sterile containers.

\section{Procedure}

Saliva was collected at room temperature between 11 a.m. and 12 noon and tests were carried out between 12 noon and 4 p.m.

\section{a) Preparation of $\mathbf{5 \%}$ Red Cell Suspension}

The freshly collected blood in an EDTA bottle was transferred into a small glass tube and centrifuged at a speed of $3000 \mathrm{rpm}$ for 15 minutes to pack the red cells. The supernatant plasma was separated as much as possible from the cells and replaced by sterile isotonic saline. This mixture was centrifuged and again the supernatant separated from the cells. This procedure was repeated 3 to 4 times to wash the red blood cells. Washing of the red blood cells was done to remove any antibody present on the cells.

After the last washing, the supernatant was removed and one drop of packed red cells was mixed with 19 drops of 
normal saline to prepare a $5 \%$ red cell suspension in isotonic saline.

\section{b) Collection and Processing of Saliva}

Saliva was collected at room temperature in sterile disposable containers. The patient was instructed to wash the mouth and drink a glass of water. One millilitre of saliva was collected in a sterile plastic bottle and transferred to a sterile test tube. The tube was then kept in a boiling water bath $\left(100^{\circ} \mathrm{C}\right)$ for twenty minutes. Saliva was boiled to destroy the enzymes present. The saliva was then centrifuged at 3000 revolutions per minute (rpm) for fifteen minutes. The supernatant was separated and diluted in a 1: 4 ratio. All the saliva samples were tested for secretor status on the same day of their collection.

\section{c) Dilution of Anti-Serum}

Anti-A and Anti-B antisera were used for patients of Blood Group A and Blood Group B and Anti-H antisera was used for patients belonging to Blood Group 0. Antisera were diluted in a dilution of 1: 8. E.g. if diluted anti-A was to be prepared, four test tubes were kept in a row and one drop of saline was put into each tube. One drop of Anti-A was now added to the first tube and mixed. Then one drop of diluted serum was taken from the first tube and added to the second tube. The same procedure was followed up to the fourth tube. (Ref) as shown in the table below:

\begin{tabular}{|c|c|}
\hline Tube & Dilution \\
\hline Tube 1 & $1: 1$ \\
\hline Tube 2 & $1: 2$ \\
\hline Tube 3 & $1: 4$ \\
\hline Tube 4 & $1: 8$ \\
\hline
\end{tabular}

One drop of processed saliva and one drop of diluted antiserum from test tube four (1: 8 dilution) were now added to fresh test tube.

\section{d) Procedure to determine Secretor Status}

The contents were mixed well and allowed to stand for fifteen minutes. Then a drop of standard red cell suspension was added and allowed to stand for sixty minutes. The mixed solution was examined under microscope. Care was taken to wash the pipette repeatedly, immediately after each dip. No agglutination suggested the presence of antigen in saliva, while agglutination suggested the absence of antigens in the saliva. Saline controls were kept simultaneously with the test.

\section{RESULTS}

The study was done to find out that there is any correlation between $\mathrm{ABO}$ blood groups, secretor status and the incidence of IHD in Kadapa district. 600 IHD patients (444 males and 156 females) and 600 control (412 males and 188 females) subjects participated in the study.

A total of 129 (21.5\%) IHD patients and 476 (79.4\%) control subjects were secretors, while 471 (78.5\%) IHD patients and $124(20.6 \%)$ control subjects were nonsecretors.

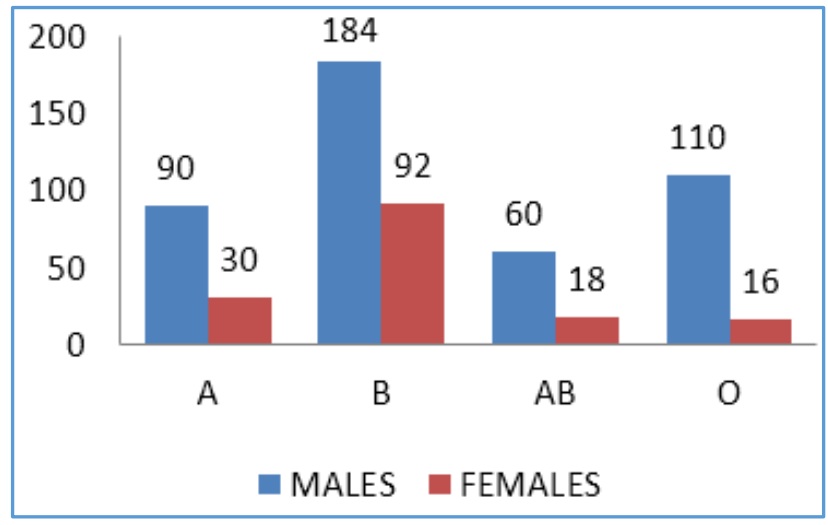

\begin{tabular}{|c|c|c|}
\hline Blood Groups & Males & Females \\
\hline A & 90 & 30 \\
\hline $\mathrm{B}$ & 184 & 92 \\
\hline $\mathrm{AB}$ & 60 & 18 \\
\hline $\mathrm{O}$ & 110 & 16 \\
\hline \multicolumn{2}{|c|}{ Table 1. Gender Wise distribution of Cases } \\
\hline
\end{tabular}

\begin{tabular}{|c|c|}
\hline Chi-square value & 19.7 \\
\hline 'P'value & 0.00005 \\
\hline
\end{tabular}

\begin{tabular}{|c|c|c|}
\hline Blood Groups & Males & Females \\
\hline A & 42 & 36 \\
\hline B & 150 & 42 \\
\hline AB & 40 & 32 \\
\hline O & 180 & 78 \\
\hline \multicolumn{2}{|c|}{ Table 2. Gender Wise distribution of Controls } \\
\hline
\end{tabular}

\begin{tabular}{|c|c|}
\hline Chi-square value & 21.8439 \\
\hline 'P' value & 0.00000 \\
\hline
\end{tabular}

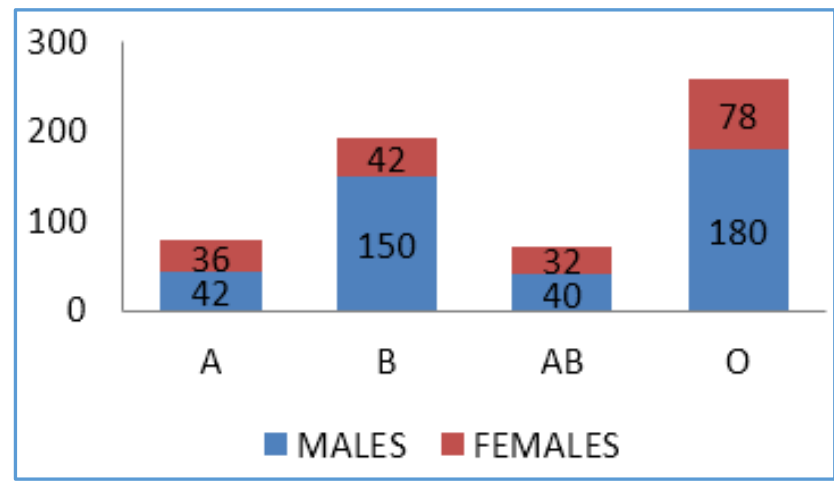

\begin{tabular}{|c|c|c|}
\hline Blood & Secretors & Non-Secretors \\
\hline $\mathrm{A}$ & 26 & 94 \\
\hline $\mathrm{B}$ & 61 & 215 \\
\hline $\mathrm{AB}$ & 18 & 60 \\
\hline $\mathrm{O}$ & 24 & 102 \\
\hline Table 3. Distribution of Secretor Status among Cases \\
\hline
\end{tabular}

\begin{tabular}{|c|c|}
\hline Chi-square value & 0.6250 \\
\hline 'P' value & 0.8907 \\
\hline
\end{tabular}




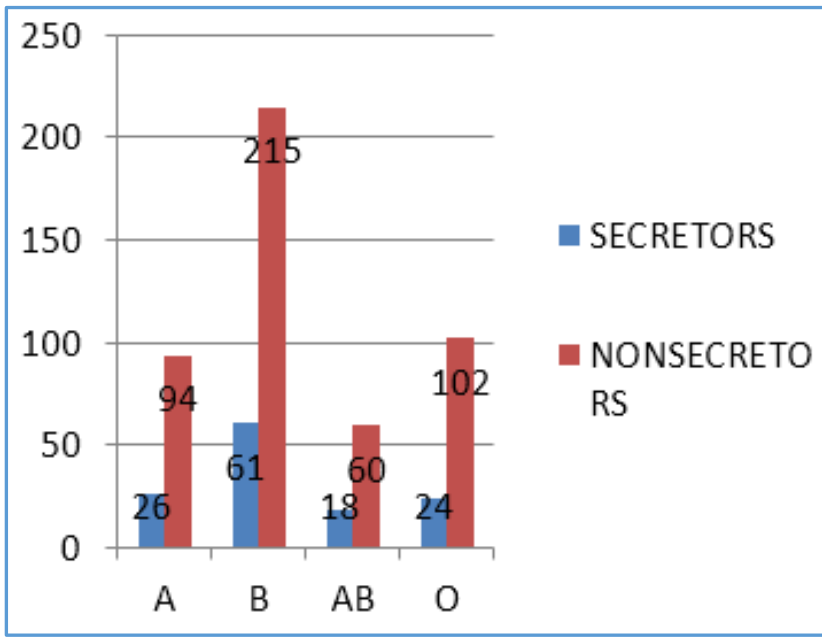

\begin{tabular}{|c|c|c|}
\hline & Secretors & Non-Secretors \\
\hline A & 63 & 15 \\
\hline B & 157 & 35 \\
\hline AB & 56 & 16 \\
\hline O & 200 & 58 \\
\hline \multicolumn{2}{|c|}{ Table 4. Distribution of Secretors and Non-Secretors } \\
among Controls \\
\hline
\end{tabular}

\begin{tabular}{|c|c|}
\hline Chi-square & 1.4179 \\
\hline 'P' value & 0.7013 \\
\hline
\end{tabular}

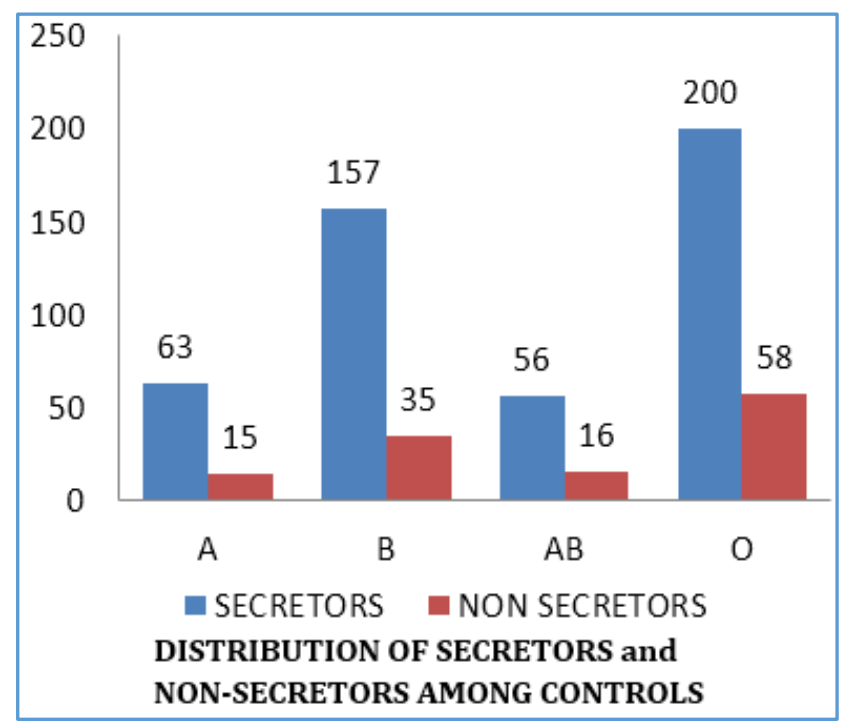

\begin{tabular}{|c|c|c|}
\hline Blood Groups & Secretors & Non-Secretors \\
\hline Cases & 129 & 471 \\
\hline Controls & 476 & 124 \\
\hline Table 5. Distribution of Secretors and Non-Secretors \\
among Cases and Controls \\
\hline
\end{tabular}

\begin{tabular}{|c|c|}
\hline Chi-square value & 401.3 \\
\hline 'P' value & 0.00000 \\
\hline
\end{tabular}

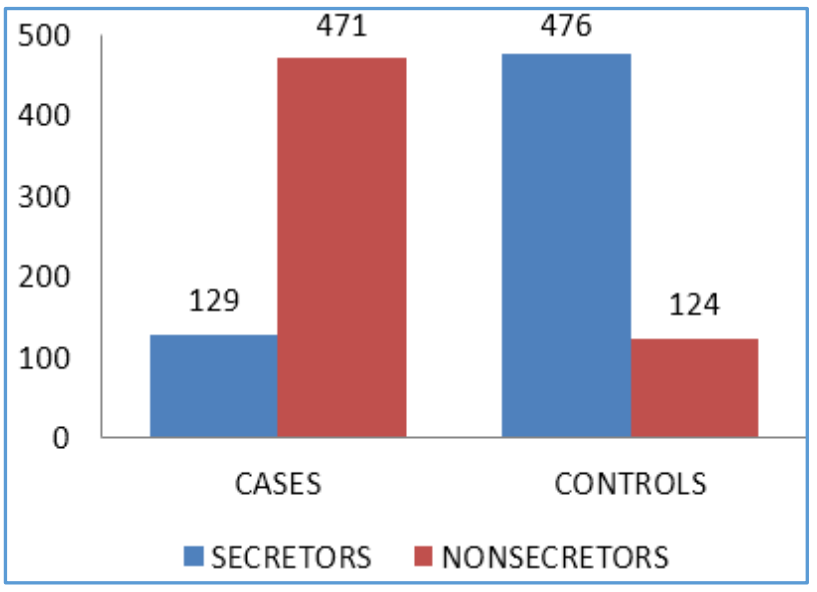

\section{DISCUSSION}

The frequency of $\mathrm{ABH}$ secretors and non-secretors in the control subjects were $79.4 \%$ (476) and $20.6 \%$ (124) respectively. Whereas, the frequencies of secretors and nonsecretors in the IHD patients were $21.5 \%$ and $78.5 \%$ respectively. The frequency of $\mathrm{ABH}$ secretor status in the control subjects in this study is generally higher than what is obtainable worldwide, where about $20.6 \%$ are nonsecretors.(10) Igbeneghu et al(11) reported a frequency of $75 \%$ secretors and 25\% non-secretors in Osogbo in south-western Nigeria, while Jaff(12) reported a frequency of $76 \%$ secretors and $24 \%$ non-secretors in Iraq. Akhter et al(13) found a frequency of $\mathrm{ABH}$ secretor status of $60 \%$ and non-secretors of $40 \%$ in Dhakar.

The FUT2 gene encodes fucosyltransferases that transfer a terminal fucose residue to a pre-existing precursor substance to form a soluble $\mathrm{H}$ antigen in secretory tissues, which serves as a precursor for soluble $\mathrm{ABH}$ antigens. Hence, individuals having at least one functional FUT2 allele, their $\mathrm{ABH}$ antigens are not only detected on their cell surfaces, but also in their body fluids including saliva. Non-secretors are homozygous for two inactive FUT2 alleles (SeSe).(14) It is therefore possible that the presence of genes that predispose a person to IHD may down-regulate the expression of FUT2 (secretor) gene and secrete enzymes, leading to the higher percentage of non-secretors in IHD patients.

\section{CONCLUSION}

The study concludes that there is a significant correlation between $\mathrm{ABO}$ blood types and secretor status. The incidence of IHD is more common in B group non-secretors in Kadapa city. This is in correlation with study done by Meian He et al(15) that non-O blood group had higher risk of Coronary Heart Disease (CHD), $(16,17,18,19)$ because factor VIII-vWF levels are a risk for CHD. (20,21) IHD was associated with 'A' blood group in studies of Saima Sharif et al(22) and was associated with 'B' group in studies of Shazia Chowdhary et al.(23)

\section{Recommendations}

To reduce the risk, lifestyle modifications like physical exercise, antioxidant rich diet like fruits, vegetables and polyunsaturated fats contained at an early age by reducing the role of risk factors for ischaemic heart disease as secretor status and $\mathrm{ABO}$ types are genetically determined.(24) 


\section{REFERENCES}

[1] Schwarz HP, Dorner F. Karl Landsteiner and his major contributions to haematology. $\mathrm{Br} \mathrm{J}$ Haematol 2003;121(4):556-65.

[2] Wisthoff CM, Reid ME. ABO and related antigens and antibodies. In: Hillyer G, Silberstein L, Ness P, et al, eds. Blood banking and transfusion medicine (Basic principles \& practice). $2^{\text {nd }}$ edn. Churchill Livingstone Elsevier 2007:69-79.

[3] Entrez Gene: ABO blood group (transferase A, alpha 13-N-acetylgalactosaminyltransferase; transferase B, alpha 1-3-galactosyl transferase).

[4] Anstee DJ. The relationship between blood groups and disease. Blood 2010;115(23):4635-43.

[5] Importance of secretor status. The blood types diets. Eat Right 4 Your Type ${ }^{\circledR}$ www.dadamo.com.

[6] Shanthi M, Puska P, Norrving B. Global atlas on cardiovascular disease prevention \& control. $1^{\text {st }}$ edn. Geneva: World Health Organization in Collaboration with the World Heart Federation \& the World Stroke Organization 2011:3-18.

[7] Mehta PK, Wei J, Wegner NK. Ischemic heart disease in women: a focus on risk factors. Trends Cardiovasc Med 2015;25(2):140-51.

[8] How is Coronary Heart Disease Treated? 29 September 2014. Archived from the original on 24 February 2015. Retrieved 25 February 2015.

[9] How can coronary heart disease be prevented or delayed? Archived from the Original on 24 February 2015. Retrieved 25 February 2015.

[10] Dacie JV, Lewis SM. Practical haematology. $8^{\text {th }}$ edn. London: Churchill Livingstone 1994.

[11] Igbeneghu C, Odaibo GN, Olisekodiaka JM, et al. ABO blood group and secretor status in HIV infection in Osogbo, south-western Nigeria. European Journal of Research in Medical Sciences 2015;3(1):1-7.

[12] Jaff MS. Higher frequency of secretor phenotype in 0 blood group-its benefits in prevention and/or treatment of some diseases. Int J Nanomedicine 2010;5:901-5.

[13] Akhter S, Kibria GM, Akhter NR, et al. ABO and Lewis blood grouping with $\mathrm{ABH}$ secretor and non-secretor status: a cross sectional study in Dhaka. Faridpur Med Coll J 2011;6(1):38-40.
[14] Rouquier S, Lowe JB, Kelly RJ, et al. Molecular cloning of a human genomic region containing the $\mathrm{H}$ blood group alpha $(1,2)$ fucosyltransferase gene and two locus related DNA restriction fragments. Isolation of a Candidate for the human secretor blood group locus. J Biol Chem 1995;270(9):4632-9.

[15] He M, Wolpin B, Rexrode K, et al. ABO blood group \& risk of coronary heart disease in two prospective studies. Arterioscler Thromb Vasc Biol 2012;32(9):2314-20.

[16] Non-O blood groups associated with higher risk of heart attack. Cardiovasc J Afr 2017;28(3):195.

[17] O'Riordan M. ABO Blood type is a risk factor for coronary heart disease. Medscape August 15, 2012.

[18] H-Al-Kawaz W, Al-Jalal LQ. Association between ABO blood group and Ischemic Heart Disease and certain Risk Factors in Basrah city. JCvD 2016. In press.

[19] Hasan MN, Chowdhury AW, Islam LMT, et al. Association of $\mathrm{ABO}$ blood group with $\mathrm{CAD}$ in patients undergoing CAG in Cardiology Department of Dhaka Medical College and Hospital. University Heart Journal 2014;10(2):81-4.

[20] Folsum AR, Wu KK, Rosamond WD, et al. Prospective study of hemostatic factors and incidence of coronary heart disease: the Atherosclerosis Risk in communities (ARIC) study. Circulation 1997;96(4):1102-8.

[21] Whincup PH, Danesh J, Walker M, et al. von Willebrand factor and coronary heart disease: prospective study \& meta-analysis. Eur Heart J 2002;23(22):1764-70.

[22] Sharif S, Anwar N, Farasat T, et al. ABO blood group frequency in Ischemic heart disease patients in Pakistani population. Pak J Med Sci 2014;30(3):593-5.

[23] Chowdhary S, Sharma V, Chowdhary S, et al. Study of association of $\mathrm{ABO}$ blood group with ischemic heart disease. International Journal of Medical Science and Public Health 2016;5(3):468-72.

[24] Gupta M, Singh N, Verma S. South Asians and cardiovascular risk: what clinicians should know. Circulation 2006;113(25):e924-9. 